\title{
Investigation on the thermal properties of new thermo-reversible networks based on poly(vinyl furfural) and multifunctional maleimide compounds
}

\author{
C. Gaina*, O. Ursache, V. Gaina, E. Buruiana, D. Ionita \\ Institute of Macromolecular Chemistry ‘Petru Poni’ Aleea Gr.Ghica Voda 41 A, RO-700487, Iasi, Romania
}

Received 24 June 2011; accepted in revised form 7 September 2011

\begin{abstract}
New thermo-reversible networks were obtained from poly(vinyl furfural) and multifunctional maleimide monomers by Diels-Alder (DA) and retro-DA reactions. The poly(vinyl furfural) having acetalization degree of 15 and $25 \%$ were obtained by the acid-catalyzed homogenous acetalization of poly(vinyl alcohol) with 2-furfural in a nonaqueous media. The thermal and viscoelastic behaviour of the cross-linked materials have been studied via differential scanning calorimetry, dynamic mechanical analysis and thermogravimetric analysis. The networks exhibit considerable swelling in those organic solvents that dissolve both poly(vinyl furfural) and bismaleimides; by heating in aprotic dipolar solvents at $150^{\circ} \mathrm{C}$, they become soluble.
\end{abstract}

Keywords: polymer synthesis, thermal properties, Diels-Alder polymers, networks

\section{Introduction}

Inspired by the phenomenon of self-healing in biological systems, the synthesis of man-made selfhealing polymeric materials has become a newly emerging paradigm and a fascinating area of research. The Diels-Alder reaction and its retro-Diels-Alder analogue represent a highly promising route to introducing self-healing properties to polymeric systems [1-5]. The search for various reversible reactions is a paramount importance for unlocking the potential of the conceptual framework of covalent constitutional dynamic chemistry [6]. The reversibility of DA reaction is widely applied to the preparation of remarkable polymers. Thermallyreversible DA reactions have been used in numerous studies including polymer synthesis from multifunctional monomers [4, 7-15] or by cross-linking of functional copolymers containing maleimide or furan pendant groups [16-22], surface modifications [16,
23], organic-inorganic polymer hybrids [24, 25], reversible crosslinking polymer chains/ gels $[5,16$, $24,26]$ and remendable/self-healing polymers [11, $12,27]$. Due to the fact that these reactions can proceed under mild conditions without a catalyst, this makes them attractive for designing covalently reversible bonds in which furan and maleimide functional groups are responsible for association and dissociation [28-31].

In this study, we report the preparation and characterization of thermo-reversible networks based on poly(vinyl furfural) and multifunctional maleimide compounds, as the basis for obtaining asymmetric membranes by the phase inversion method. Thermoreversible nature of the Diels-Alder networks was characterized by FTIR, ${ }^{1} \mathrm{H}-\mathrm{NMR}$ and by a heatingcooling cycle in differential scanning calorimetry (DSC) using a model compound based on poly(vinyl furfural) and mono-maleimide compound. The ther-

\footnotetext{
${ }^{*}$ Corresponding author, e-mail: gcost@icmpp.ro
}

(c) BME-PT 
mal and mechanical properties of the polymers were characterized by thermogravimetric analysis and dynamic mechanical analysis.

\section{Experimental}

\subsection{Reagents and materials}

Poly(vinyl alcohol) (PVA), white crystalline form (Aldrich reagent, viscosity-average molecular weight $77000-79000$ containing 2\% of acetate group), 2-furaldehyde, 99\% (Aldrich, USA), dimethylformamide (DMF), dimethylsulfoxide (DMSO), polycaprolactone diol having numeric-average molecular weight of 1250 (Aldrich, USA), $p$-toluene sulfone acid ( $p$-TSA) were used as received. 4-Maleimidobenzoyl chloride was synthesized as described in the literature [32].

4,4'-bismaleimidodiphenylmethane (BMI-1), 4,4'bismaleimidodiphenyloxide (BMI-2) and 1,1'-hexamethylene bismaleimide (BMI-3) were synthesized from diamines $(1 \mathrm{~mol})$ and maleic anhydride ( 2 moles) in dry acetone according to a two-step method described in the literature [33].

\subsubsection{Synthesis of bismaleimide (BMI-4) and maleimide (MI)}

The bismaleimide containing urethane groups (BMI-4) was prepared by the addition reaction of 4-maleimidophenyl isocyanate with polycaprolactone diol having numeric-average molecular weight of 1250 (Aldrich, USA) according to a method described in our previous paper [34].

BMI-4, yellow wax from dichloromethane, yield $82 \%$.

FTIR (KBr): 3323, 3085, 2947, 2865, 1735, 1707, 1608, 1534, 1462, 1398, 1314, 1240, 1160, 1105, $1070,834,689 \mathrm{~cm}^{-1}$.

${ }^{1} \mathrm{H}-\mathrm{NMR}\left(\mathrm{CDCl}_{3}\right): \delta=7.55(\mathrm{~d}, 4 \mathrm{H}$, aromatic protons), $7.08(\mathrm{~d}, 4 \mathrm{H}$, aromatic protons), $6.80(\mathrm{~s}, 4 \mathrm{H}$, maleimide protons), 5.35 (s, $2 \mathrm{H}, \mathrm{NH}$ proton), 4.05 (t, $\left.20 \mathrm{H}, \mathrm{COOCH}_{2}\right), 3.75$ (t, $\left.4 \mathrm{H}, \mathrm{NHCOOCH}_{2}\right), 2.35$ (t, 20H, $\left.\mathrm{CH}_{2} \mathrm{COO}\right), 1.45$ (m, $160 \mathrm{H}, \mathrm{CH}_{2}-\mathrm{CH}_{2}-$ ).

4-nonylphenyl 4-(2,5-dioxo-2,5-dihydro-1 $\mathrm{H}$-pyrrol1-yl)benzoate (MI) was prepared by the reaction of 4-maleimidobenzoyl chloride with $p$-nonylphenol, in chloroform, in the presence of triethylamine. A typical procedure is presented below. To a solution of 4-maleimidobenzoyl chloride $(0.01 \mathrm{~mol}, 2.35 \mathrm{~g}$ ) in chloroform $(40 \mathrm{ml})$ cooled at $0-5^{\circ} \mathrm{C}$, triethylamine $(1.4 \mathrm{ml})$ and $p$-nonylphenol $(0.01 \mathrm{~mol}, 2.2 \mathrm{~g})$ were added. The reaction mixture was stirred at 0 $5^{\circ} \mathrm{C}$ for 2 hours, at room temperature for 2 hours and at reflux for 1 hour and then was filtered. The organic layer was washed with water. After removing of chloroform, $4 \mathrm{~g}$ of yellow wax product was obtained (yield 90\%).

${ }^{1} \mathrm{H}-\mathrm{NMR}\left(\mathrm{CDCl}_{3}\right): \delta=8.24(\mathrm{~d}, 2 \mathrm{H}$, aromatic protons), $7.63(\mathrm{~d}, 2 \mathrm{H}$, aromatic protons), 7.38 (dd, $2 \mathrm{H}$, aromatic protons), $7.23(\mathrm{~d}, 2 \mathrm{H}$, aromatic protons), 6.88 (s, 2H, maleimide protons), $1.70\left(\mathrm{~m}, 2 \mathrm{H}, \mathrm{CH}_{2}\right)$, $1.38\left(\mathrm{~m}, 14 \mathrm{H},\left(\mathrm{CH}_{2}\right)_{7}\right)$ and $0.80\left(\mathrm{t}, 3 \mathrm{H}, \mathrm{CH}_{3}\right)$.

\subsubsection{Synthesis of poly(vinyl furfural) (PVF)}

PVF was prepared by acetalization of PVA in DMSO as solvent, in the presence of $p$-TSA according to a method described in literature [35-36]. The degree of acetalization was determined by ${ }^{1} \mathrm{H}-\mathrm{NMR}$ spectra using Equation (1) [37]:

$$
(F A)=\frac{2}{\frac{A_{\mathrm{CH}_{2}}}{A_{\mathrm{H}_{5}}}-2}
$$

where (FA) is the mol\% of vinyl acetal, $A_{\mathrm{CH}_{2}}$ represents the total peak area of methylene protons and $A_{\mathrm{H}_{5}}$ represents peak area of the $\mathrm{H}_{5}$ protons which appears at $7.6 \mathrm{ppm}$.

A typical procedure is presented below. PVA (11 g, $0.25 \mathrm{~mol}$, based on $-\mathrm{CH}_{2}-\mathrm{CH}-\mathrm{OH}$ as unit) was dissolved in DMSO $(200 \mathrm{ml})$ in a round bottom flask. Then, $p$-TSA $(2 \mathrm{~g}, 1 \% \mathrm{w} / \mathrm{v}$ of the reaction medium) and 2 -furaldehyde $(10 \mathrm{ml}, 0.12 \mathrm{~mol})$ was added. The reaction mixture was heated and stirred at $60^{\circ} \mathrm{C}$ for 24 hours, then cooled at room temperature and poured in water. The solid was filtered, then washed well with water and finally dried in a vacuum oven at $60-65^{\circ} \mathrm{C}$ for 24 hours, yield $82 \%$.

\subsubsection{Synthesis of model compound (PVF-MI)}

To a solution of PVF-2 ( $0.5 \mathrm{~g})$ in DMF (20 ml), MI $(1.5 \mathrm{~g})$ was added and stirred at $80^{\circ} \mathrm{C}$ for 8 hours. The solution was cooled and precipitated in water, then dried. The product was purified by dissolving in acetone and precipitation in water.

\subsubsection{Preparation of cross-linked polymers via $\mathrm{DA}$ reaction of $\mathrm{PVF}$ with bismaleimide (BMI)}

A mixture of PVF and BMI (2DS:1 by mols) was dissolved in DMF $(10 \mathrm{ml})$ and stirred at $80-90^{\circ} \mathrm{C}$ 
for 4 hours. The reaction solution was degassed in vacuum and quickly transferred to a glass plate, using a doctor blade $(e=1 \mathrm{~mm})$. The solvent was evaporated in atmosphere at $80-90^{\circ} \mathrm{C}$ for 24 hours. The film was removed from the glass plate by soaking in cold water.

\subsection{Measurements} recorded on a Bruker Vertex 70 Instruments (Austria) equipped with a Golden Gate single reflection ATR accessory, spectrum range $600-4000 \mathrm{~cm}^{-1}$.

The proton nuclear magnetic resonance ( $\left.{ }^{1} \mathrm{H}-\mathrm{NMR}\right)$ spectra were recorded on a Bruker NMR spectrometer, Avance DRX $400 \mathrm{MHz}$ (Rheinstteten, Germany), using DMSO- $\mathrm{d}_{6}$ and $\mathrm{CDCl}_{3}$ as solvents and tetramethylsilane as an internal standard.

Thermogravimetric analyse (TGA) was carried out in air atmosphere using a DERIVATOGRAF Q$1500 \mathrm{D}$ apparatus (Hungary). The rate of TGA scans was $10^{\circ} \mathrm{C} / \mathrm{min}$. The initial weight of the samples was about $50 \mathrm{mg}$ and the temperature range 30 $700^{\circ} \mathrm{C}$.

Differential scanning calorimetry (DSC) measurements were conducted on a DSC 200 F3 Maia (Netzsch, Germany). About $9 \mathrm{mg}$ of sample were heated in pressed and punched aluminium crucibles at a heating rate of $10^{\circ} \mathrm{C} /$ minute. Nitrogen was used as inert atmosphere at a flow rate of $100 \mathrm{ml} /$ minute. A Perkin Elmer DSC-7 differential scanning calorimeter (Massachusetts, USA) was used for thermal analysis and was operated at a heating rate of $10^{\circ} \mathrm{C} / \mathrm{min}$.
The Fourier transform infrared (FTIR) spectra were

Tests were conducted on samples of about $10 \mathrm{mg}$, which were gradually heated for observation of the glass-transition temperature.

Dynamic mechanical experiments (DMA) were made using a Diamond PerkinElmer instrument (Singapore) that applies a sinusoidal stress to the sample and measures the resulting strain. The force amplitude used was well within the linear viscoelastic range for all investigated samples. The thermomechanical properties were evaluated, starting from $-100^{\circ} \mathrm{C}$ up to beyond the temperature corresponding to glass transition, at a heating rate of $2^{\circ} \mathrm{C} / \mathrm{min}$ and a frequency of $1 \mathrm{~Hz}$, under nitrogen atmosphere. The size of films was of $10 \mathrm{~mm} \times$ $10 \mathrm{~mm} \times 0.5 \mathrm{~mm}$ for the tension attachment.

Wide-angle X-ray diffractions (WAXD) of the polymers were recorded in a Bruker AD8 Advance diffractometer (Germany) using a $\mathrm{Cu}-\mathrm{K}_{\alpha}$ source, at room temperature.

\section{Results and discussion}

\subsection{Characterization of PVF-(1,2)}

By acetalization of PVA with furfural in DMSO in the presence of $p$-TSA was obtained PVF with the acetalization degree of $15 \%$ (PVF-1) and 25\% (PVF-2). A typical ${ }^{1} \mathrm{H}-\mathrm{NMR}$ spectrum for PVF-2 is shown in Figure 1. The signals observed at 1.30-1.90, $3.83-3.99,5.57,6.43$ and $7.61 \mathrm{ppm}$ are attributed to the methylene $\left(-\mathrm{CH}_{2}-\right)$, methine $(-\mathrm{CH}<)$, dioxymethine $(-\mathrm{O}-\mathrm{CH}-\mathrm{O}-)$ and furan ring protons, respectively.
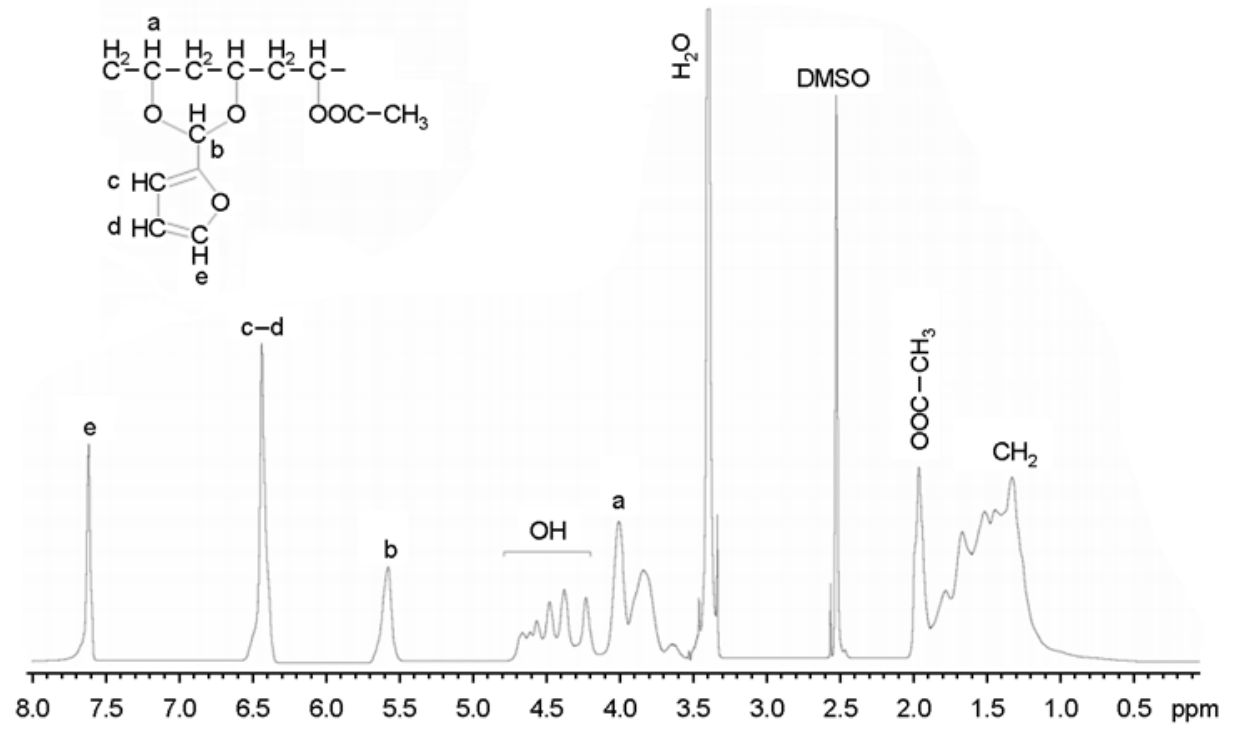

Figure 1. The ${ }^{1} \mathrm{H}-\mathrm{NMR}$ spectrum for PVF-2 


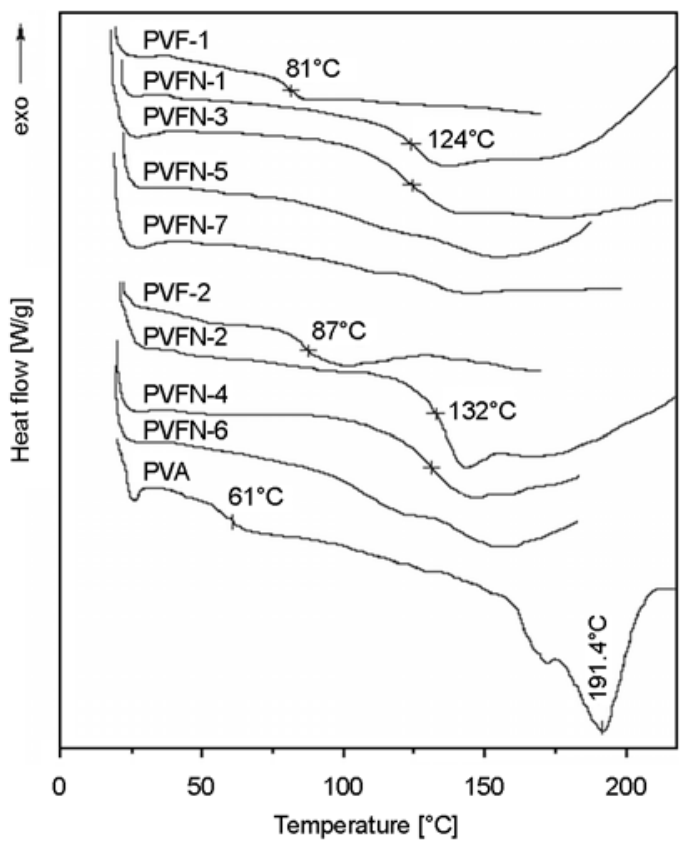

Figure 2. The DSC curves of PVA, PVF and PVFN films at second heating run films

The DSC measurements of PVA and PVF films are presented in Figure 2. The DSC scan of PVA shows a transition corresponding to the glass transition temperature at $61^{\circ} \mathrm{C}$ and an endothermic peak around $191^{\circ} \mathrm{C}$ attributed to the melting temperature

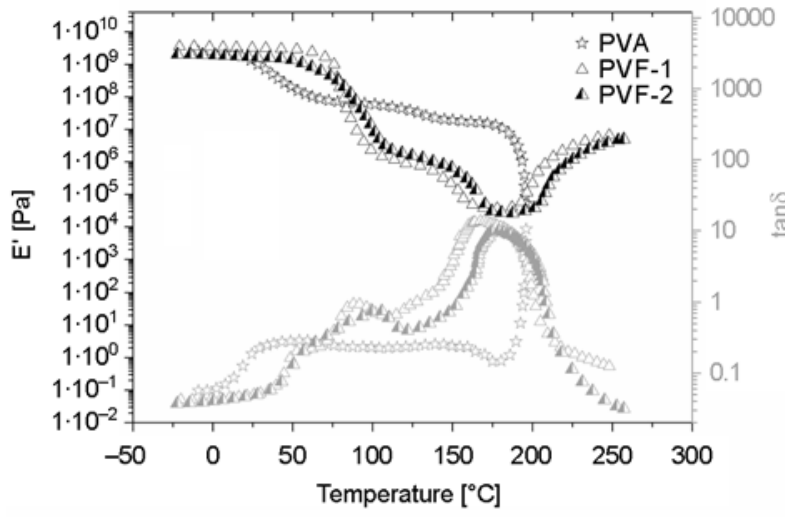

Figure 3. The storage modulus and dissipation factor $\tan \delta$ profiles of PVA, PVF-1 and PVF-2 with frequency of $1 \mathrm{~Hz}$

of PVA. The DSC scans of PVF-1 and PVF-2 show a transition temperature around 81 and $87^{\circ} \mathrm{C}$, respectively. Glass transition temperature of PVF increases with the increase of acetalization degree [38].

The variations of the dynamic mechanical properties with temperature for PVA, PVF-1 and PVF-2 are presented in Figure 3. The viscoelastic results obtained for these three samples are summarized in Table 1. All three samples are characterized at low temperatures by a glassy behaviour. This was indicated by the relatively constant value of the storage

Table 1. Dynamic mechanical analysis of PVF-(1-2) and PVFN-(1-8)

\begin{tabular}{|c|c|c|c|c|c|c|}
\hline \multirow{3}{*}{ Sample } & \multicolumn{3}{|c|}{ DMA } & \multicolumn{3}{|c|}{ Storage modulus at } \\
\hline & \multirow{2}{*}{$\begin{array}{c}\mathbf{T}_{\mathbf{g}}{ }^{2} \\
{\left[{ }^{\circ} \mathbf{C}\right]}\end{array}$} & \multicolumn{2}{|c|}{$\tan \delta$ peak } & \multirow{2}{*}{$\begin{array}{c}\mathbf{2 0}^{\circ} \mathrm{C} \\
{[\mathrm{MPa}]}\end{array}$} & \multirow{2}{*}{$\begin{array}{l}170^{\circ} \mathrm{C} \\
{[\mathrm{MPa}]}\end{array}$} & \multirow{2}{*}{$\begin{array}{l}250^{\circ} \mathrm{C} \\
{[\mathrm{MPa}]}\end{array}$} \\
\hline & & Temperature $\left[{ }^{\circ} \mathrm{C}\right]$ & Height & & & \\
\hline PVF-1 & 71.9 & $86.9 ; 163.8$ & $0.93 ; 13.26$ & 3063 & 0.039 & 6 \\
\hline PVFN-1 & 109.3 & $136 ; 180 ; 232$ & $0.56 ; 0.25 ; 0.137$ & 1910 & 3.250 & 532 \\
\hline PVFN-3 & 97.4 & $123.5 ; 178.6 ; 236$ & $0.56 ; 0.26 ; 0.151$ & 2019 & 3.311 & 1034 \\
\hline PVFN-5 & 68.2 & $87.4 ; 123 ; 168$ & $0.65 ; 1.56 ; 3.50$ & 596 & 0.096 & 1.72 \\
\hline PVFN-7 & 72.7 & $89.6 ; 168$ & $0.51 ; 5.28$ & 290 & 0.047 & - \\
\hline PVF-2 & 66.3 & $100.7 ; 178.8$ & $0.77 ; 10.06$ & 1728 & 0.027 & 0.263 \\
\hline PVFN-2 & 118.5 & $140.6 ; 156$ & $0.408 ; 0.471$ & 1781 & 4.455 & 108 \\
\hline PVFN-4 & 113.0 & $133 ; 179 ; 241$ & $0.50 ; 0.20 ; 0.12$ & 1412 & 4.099 & 161 \\
\hline PVFN-6 & 96.2 & $89.6 ; 124 ; 195$ & $0.51 ; 0.78 ; 0.119$ & 809 & 4.600 & 36.10 \\
\hline PVFN-8 & 40.0 & $74.2 ; 180$ & $0.38 ; 4.65$ & 101 & 0.017 & 4.40 \\
\hline
\end{tabular}

${ }^{a}$ Glass transition temperature by DMA measurements, corresponded to onset temperature of the decrease in $E^{\prime}$

Table 2. Dynamic mechanical data of PVA, PVF-1 and PVF-2

\begin{tabular}{|c|c|c|c|c|c|c|c|}
\hline \multirow{2}{*}{ Sample } & \multirow{2}{*}{$\begin{array}{c}\mathrm{E}^{\prime} \cdot 10^{9 \mathrm{a}}\left(\approx-6^{\circ} \mathrm{C}\right) \\
{[\mathrm{Pa}]}\end{array}$} & \multicolumn{4}{|c|}{$\mathrm{T}_{\mathrm{g}}$ of amorphous phase $\left[{ }^{\circ} \mathrm{C}\right]$} & \multicolumn{2}{|c|}{$\tan \delta$ of crystalline phase } \\
\hline & & $\mathbf{E}_{\text {onset }^{\prime}}{ }^{\mathbf{n}}$ & $\mathrm{E}_{\text {max }}^{\prime c}$ & \multicolumn{2}{|c|}{$\tan \delta$ peak } & $\mathbf{T}\left[{ }^{\circ} \mathbf{C}\right]$ & Height \\
\hline PVA & 3.7 & 34.9 & 42.4 & \multicolumn{2}{|c|}{54.4} & $\begin{array}{l}\text { Shoulder } \\
113-152\end{array}$ & 0.15 \\
\hline \multirow{2}{*}{ PVF-1 } & \multirow{2}{*}{3.0} & \multirow{2}{*}{$39.8 ; 71.9$} & \multirow{2}{*}{$46.3 ; 74.4$} & \multirow{2}{*}{$\begin{array}{c}\text { Shoulder } \\
51.7\end{array}$} & \multirow{2}{*}{$\begin{array}{c}\text { Peak } \\
86.9\end{array}$} & 167.0 & 13.53 \\
\hline & & & & & & \multirow[b]{2}{*}{174.5} & \multirow[b]{2}{*}{9.72} \\
\hline PVF-2 & 2.0 & 41.7 & $\begin{array}{c}66.3 \\
\text { (broad peak) }\end{array}$ & $58.7 ; 85.8$ & 100.7 & & \\
\hline
\end{tabular}

aStorage modulus corresponding to glass region;

${ }^{\mathrm{b}}$ Glass transition temperature of sample by DMA measurement, corresponded to onset temperature of the decrease in $E^{\prime}$;

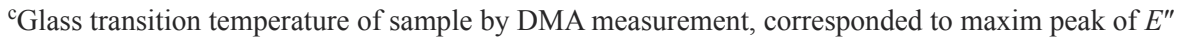


modulus whose magnitude is over $10^{9} \mathrm{~Pa}$ (Table 2). In this region, the macromolecules are in frozen state, the polymers being stiff and glassy. As is depicted in the $E^{\prime}-T$ curve the rigidity of the three polymers in the glassy region decreases in the order: PVA $>$ PVF-1 $>$ PVF-2. Consequently, the storage modulus diminishes as furfural content increases suggesting an increasing in mobility of macromolecular chains. The explanation is relative simple: by introduction of furfural units, the cleavage of the intra- and intermolecular hydrogen bonds between hydroxyl groups takes place, the rigidity induced by these bonds decreases, the free volume increases and the sample presents a more flexible structure.

The storage modulus of the PVA decreases with increasing temperature and drops at $13^{\circ} \mathrm{C}$. The drop of $E^{\prime}$ and two peaks of $E^{\prime \prime}$ and $\tan \delta$ centred at 42.4 and $54.4^{\circ} \mathrm{C}$, respectively can be attributed to the glass transition of the amorphous phase [39-41]. Moreover, the small decrease of $E^{\prime}$ modulus from $3 \cdot 10^{9}$ to $6 \cdot 10^{7} \mathrm{~Pa}$, less than two orders of magnitude indicates the presence of restraints which impede the coordinated motion of macromolecular chains. These restraints could originate from the higher crystallinity of PVA which appeared as a result of planar zig-zag conformation. For PVF-1 the two drops that appear on the $E^{\prime}$ curve at 39.8 and $71.9^{\circ} \mathrm{C}$, the peaks on $E^{\prime \prime}\left(46.3\right.$ and $74.4^{\circ} \mathrm{C}$ ) and $\tan \delta$ curve $\left(51.7\right.$ and $\left.86.9^{\circ} \mathrm{C}\right)$ indicate the presence of two relaxation phenomena (Table 2). A rapid drop of storage modulus of PVF-2 from $1.6 \cdot 10^{9}$ to $1.7 \cdot 10^{6} \mathrm{~Pa}$ relates to the glass transition. The fall of the storage modulus is accompanied by a large peak on the $E^{\prime \prime}$ curve with a maximum at $66.3^{\circ} \mathrm{C}$. Analyzing the plot $\tan \delta$ versus temperature in the range of 50 $120^{\circ} \mathrm{C}$ a characteristic peak, centred at $100.7^{\circ} \mathrm{C}$, was observed accompanied by two shoulders: one centred at $58.7^{\circ} \mathrm{C}$ and the other at $85.8^{\circ} \mathrm{C}$.

The variation of $\tan \delta$ as a function of temperature at a frequency of $1 \mathrm{~Hz}$ is represented in Figure 3. DMA spectra shows a shift of the $\alpha$ peak to higher temperatures with increasing furfural content and a reduction of relaxation strength from 0.93 in the case of PVF-1 to 0.77 in the case of PVF-2. Taking into account that the height of $\tan \delta$ peak is governed by the molecular mobility there can be concluded that with increasing furfural content a diminution in mobility appears.

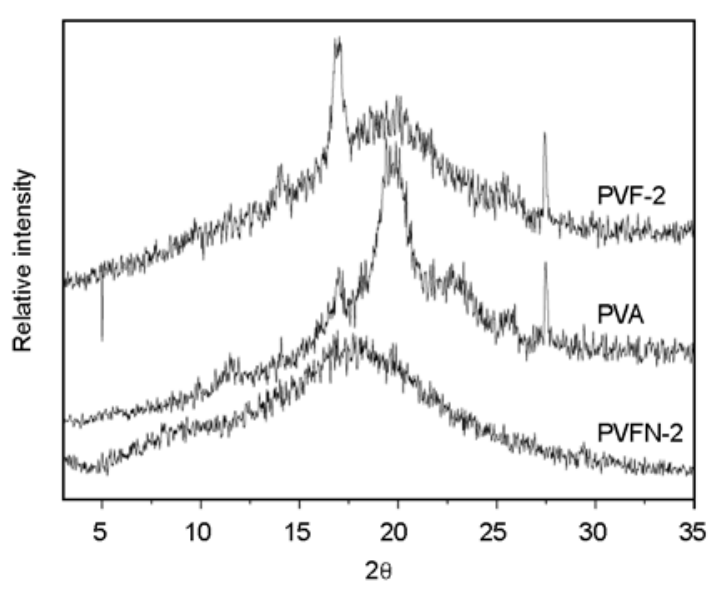

Figure 4. XRD patterns of the PVA, PVF-2 and PVFN-2

At a temperature higher than $100^{\circ} \mathrm{C}$, literature studies mention two relaxations of the crystalline phase at 135 and $237^{\circ} \mathrm{C}$, respectively. The first one is attributed to the local relaxation of the crystalline phase, while the second one is caused by the melting of the crystalline domains [39-41]. In our case the first peak of PVA is shifted to higher temperatures $\left(147.6^{\circ} \mathrm{C}\right)$, while the melting of the crystalline domains could not be observed. In PVF-1 and PVF-2 there is an increase in the $\tan \delta$ temperature at which this relaxation appears, as well as a decrease in strength with increasing furfural content. A possible explanation consist of the restrictive molecular motions appeared as a result of the crosslinking reactions confirmed by the abrupt increase of the storage modulus at temperatures higher than $190^{\circ} \mathrm{C}$. Since the furfural rings do not fit into the crystal lattice of PVA, the degree of crystallinity decreases. The (unreacted) hydroxyl functions, which are distributed randomly as well, can only lead to a very limited degree of crystallinity in PVF. This explanation is confirmed by wide-angle $\mathrm{X}$-ray diffraction (WAXD) measurements (see Figure 4). The peak with $\theta=19.8^{\circ}$ corresponds to the (110) reflection, i.e., a plane containing the planar zigzag chain direction of the crystallites.

\subsection{Characterization of PVFN networks}

DA cycloaddition reaction was used in cross-linking poly(vinyl furfural) with multifunctional maleimide (Figure 5). The DA reaction was carried out between PVF-1 or PVF-2 and bismaleimide monomers (BMI). The furan rings in the PVF-1 or PVF-2, part of the polymer, and the maleimide 


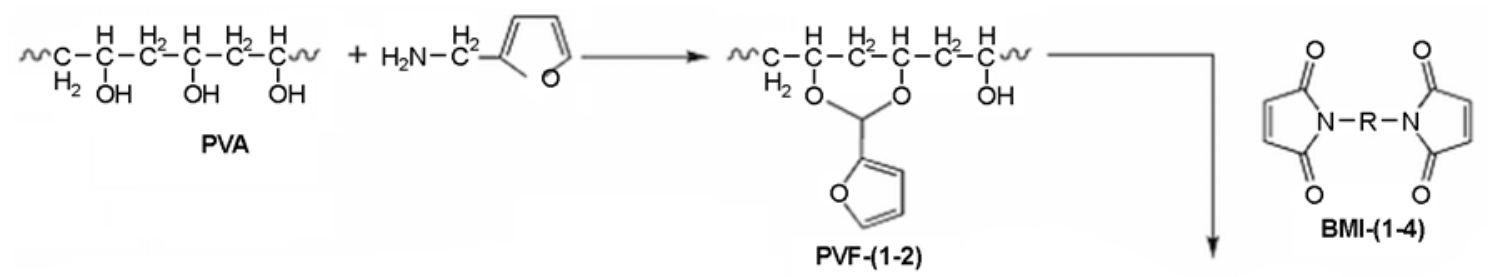

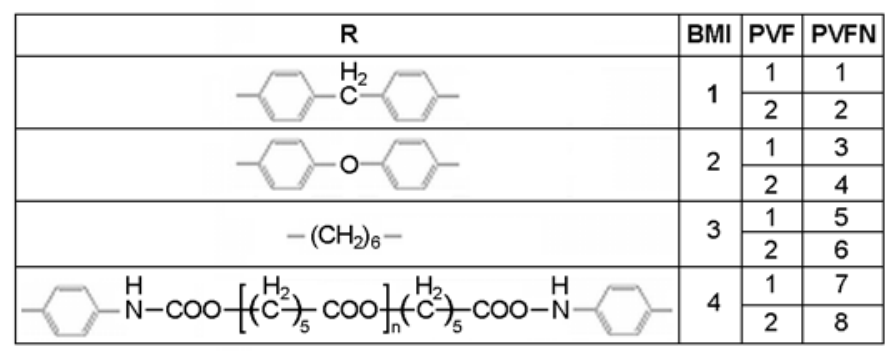

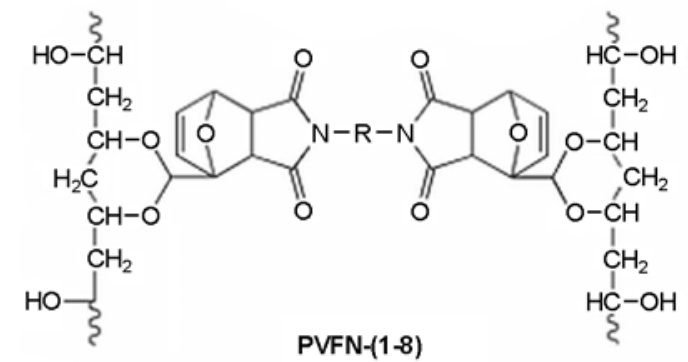

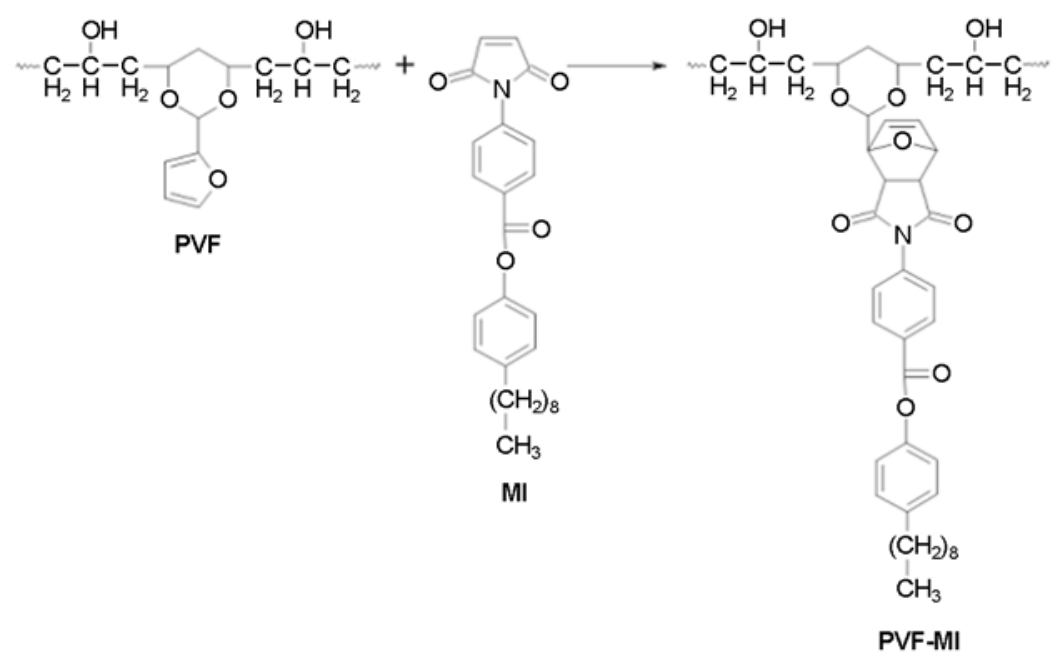

Figure 5. Synthesis of networks PVFN-(1-8)

group in the BMI acted as the diene and dienophile, respectively. Stoichiometric quantities of PVF-1 and BMI (2:1 mols) were dissolved in DMF and stirred at $80-90^{\circ} \mathrm{C}$ for 4 hours. The reaction mixture was degassed and transferred to a glass plate and the solvent was evaporated at $80-90^{\circ} \mathrm{C}$ for 24 hours. The film was removed from the glass plate by soaking in cold water. Figure 6 represents the ATR-FTIR spectra of the PVF-1 and their network materials. The spectrum of $\mathbf{P V F}-1$ shows characteristic peaks at $1506 \mathrm{~cm}^{-1}(\mathrm{C}=\mathrm{C}$ in furan ring $), 1103 \mathrm{~cm}^{-1}(\mathrm{C}-\mathrm{O}$ in furan ring), $1004 \mathrm{~cm}^{-1}$ (furan ring breathing) and $750 \mathrm{~cm}^{-1}$ (monosubstituted furan ring) [12]. The ATR-FTIR spectrum of networks shows a new absorption band about $1776 \mathrm{~cm}^{-1}$ attributed to the existence of DA adduct from the reaction between furan and maleimide groups [12, 42] and at $1190 \mathrm{~cm}^{-1}$ assigned to $v_{\mathrm{C}-\mathrm{N}-\mathrm{C}}$ from cycoadduct. The strong absorption of the $>\mathrm{C}=\mathrm{O}$ stretching shifted from $1730 \mathrm{~cm}^{-1}$ (in PVF-1) to $1705 \mathrm{~cm}^{-1}$ (in network) due to the interaction between PVF and bismaleimide.

The PVFN-(1-8) network materials are not soluble in those organic solvents that dissolve both PVF and BMI, but they swell in them. By heating of PVFN-(1-8) in aprotic dipolar solvents (DMF, NMP or DMSO) at $150^{\circ} \mathrm{C}$ for $30-60$ minutes, they become soluble. For example, a fluid solution of PVFN-8 in DMF ( $5 \mathrm{wt} \%$ ) formed by retro-DA reaction of network in DMF at $150^{\circ} \mathrm{C}$ for 1 hour (Figure 7a) becomes gel by maintaining it at $80^{\circ} \mathrm{C}$ for 3 hours (Figure $7 b$ ).

\subsubsection{Thermal properties}

The thermo-reversible properties of network materials are characterized by DSC analysis. Typical 


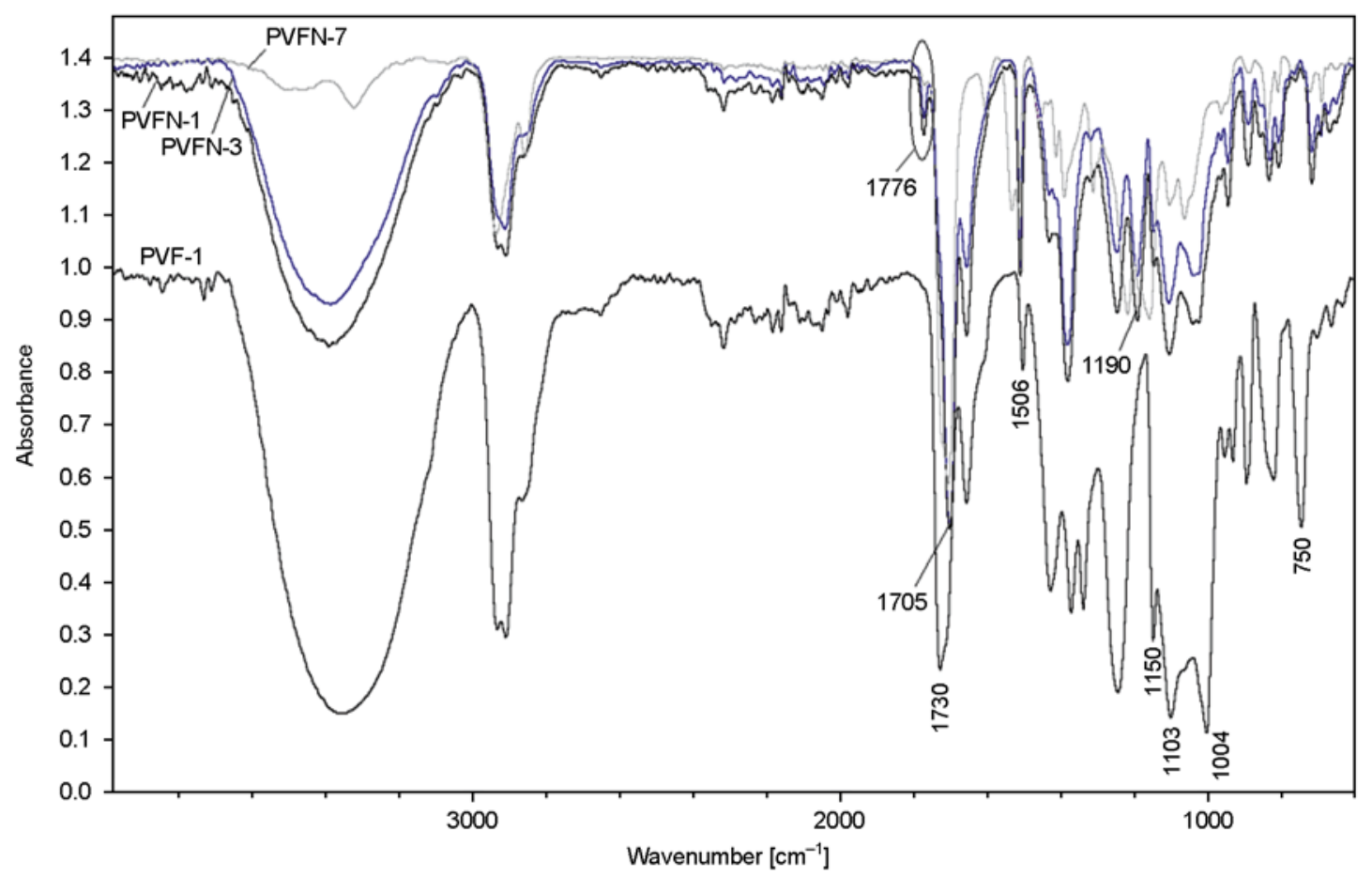

Figure 6. The ATR-FTIR spectra of the PVF-1 and their network materials

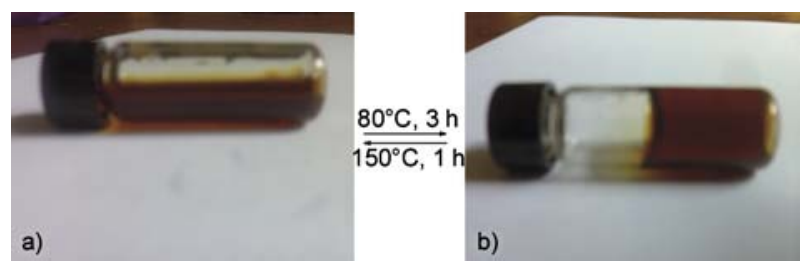

Figure 7. Photograph of observation of the thermally reversible cross-linking behaviour of PVFN-8

dynamic DSC curves of PVF and BMI systems are presented in Figure 2. As can be seen, in the case of polymers based on BMI-(1,2) with a higher rigidity, $T_{\mathrm{g}}$ shifts to higher values and the retro-DA process overlaps with the glass transition. The polymers based on BMI- $(\mathbf{3 , 4})$ present lower $T_{\mathrm{g}}$ and the retro-DA process takes place after the glass transition.

To facilitate the investigation by ${ }^{1} \mathrm{H}-\mathrm{NMR}$ spectroscopy of the DA and retro-DA reactions of poly (vinyl furfural) with maleimide, a model compound was synthesized by the reaction of PVF-2 and mono-maleimide compound (MI) (Figure 5). The ${ }^{1} \mathrm{H}-\mathrm{NMR}$ spectrum of model compound shows in addition to the chemical shifts characteristic to the PVF structure, and signals attributed to maleimide organic rest at $0.80-1.70,6.88,7.38,7.63$ and 8.24 ppm due to $\mathrm{CH}_{3}$ and $\mathrm{CH}_{2}$ protons from nonyl rest and aromatic protons and at 6.60, 5.37, 5.28 and $3.10-3.30 \mathrm{ppm}$ corresponding to the protons of maleimide-furan cycloadduct (Figure 8a). By heating the solution at $150^{\circ} \mathrm{C}$ for 30 minutes, the ${ }^{1} \mathrm{H}-\mathrm{NMR}$ spectrum shows the disappearance of chemical shifts characteristic to the cycloadduct protons and the appearance of new signals at 7.20, 7.55 and $6.41 \mathrm{ppm}$ attributed to the maleimide and furan protons indicating that the retro-DA reaction occurred entirely (Figure 8b). By cooling the sample at room temperature there can be observed the partial recovery of cycloadduct (Figure 8c). Maintaining the sample at $80^{\circ} \mathrm{C}$ for 3 hours leads to total recovery of cycloadduct.

Retro-DA and DA reactions were also studied by DSC measurements, applying heating-cooling cycles for PVF-MI (Figure 9a). The h1 curve shows the first heating cycle of the cross-linked PVF-MI heated at $50-180^{\circ} \mathrm{C}$ with a heating rate of $10^{\circ} \mathrm{C} / \mathrm{min}$. It has an inflexion around $98^{\circ} \mathrm{C}$ attributed to the glass transition temperature of sample and a large endothermic peak at $143^{\circ} \mathrm{C}$ which indicated the cleavage of the DA cycloadduct. In the second (h2) and the third (h3) heating run the compound has the same behaviour as in the first one, this fact being a proof of it's thermo-reversible nature. The increase of the glass transition temperature from $98^{\circ} \mathrm{C}$ for the first heating run to $99^{\circ} \mathrm{C}$ for the third heating cycle is probably due to the dehydration reactions of PVF polymer. 

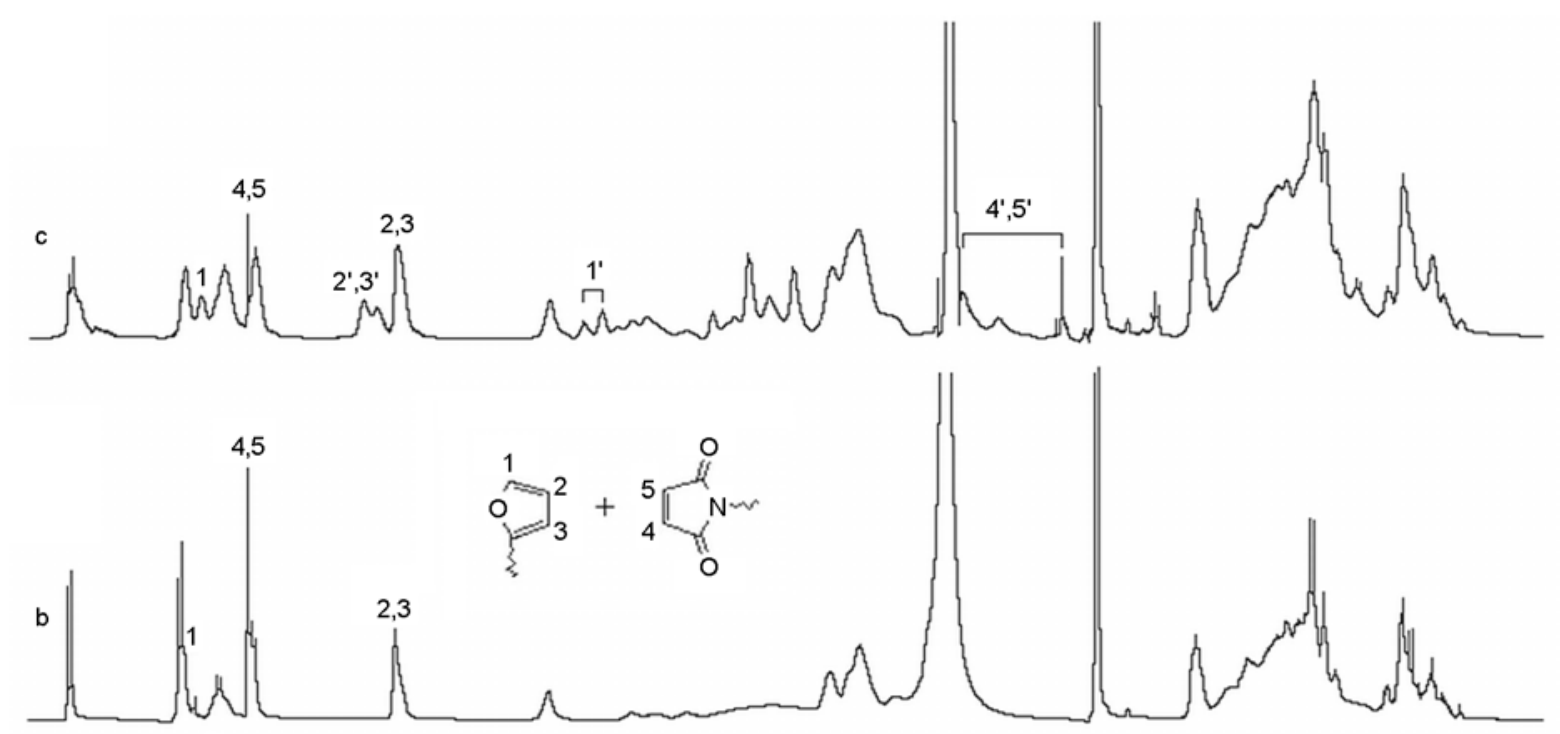

$\overbrace{3}^{1}+\underbrace{2}_{0}$

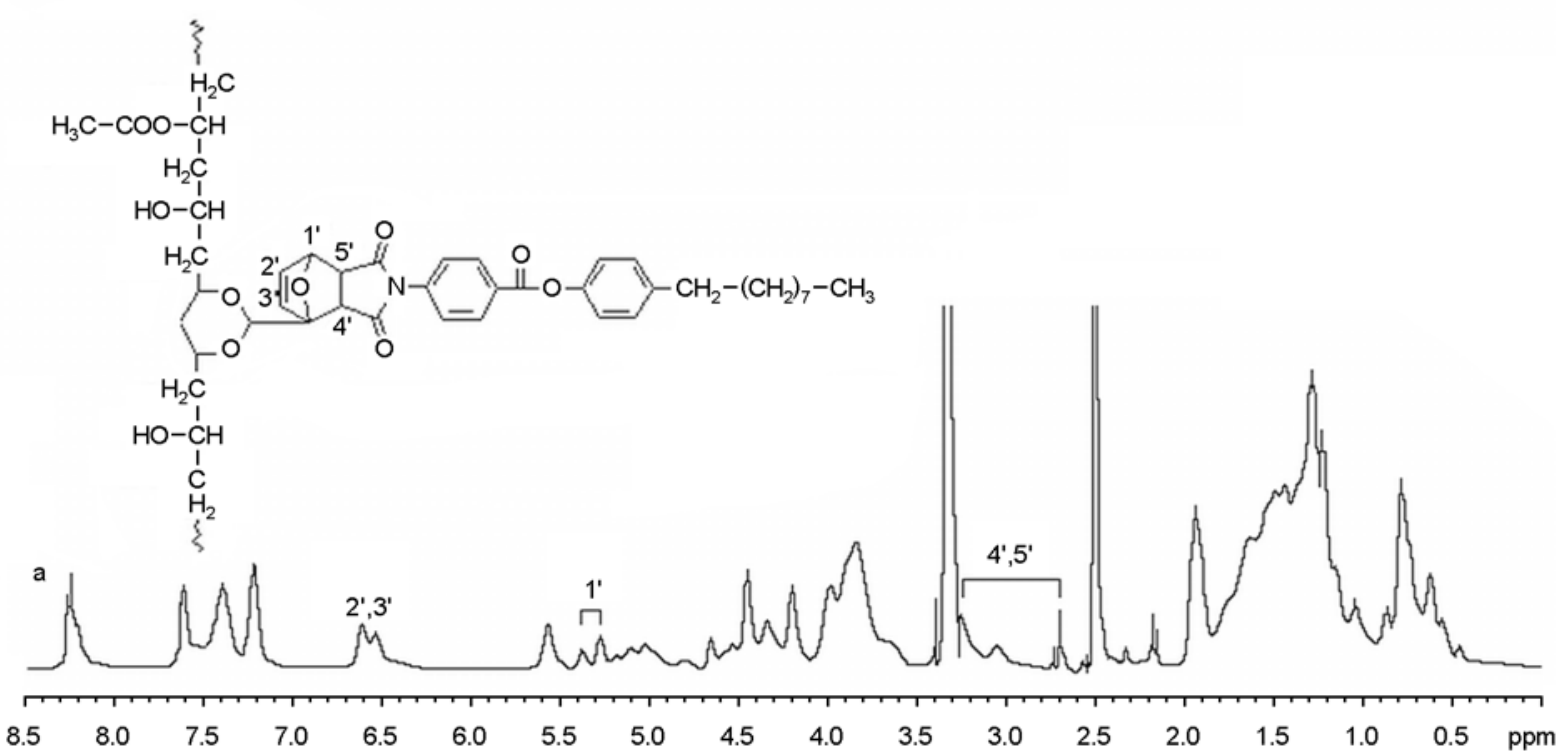

Figure 8. The ${ }^{1}$ H-NMR spectrum for model compound: a) adduct of PVF-2 and MI; b) retro-DA product obtaining by heating the adduct at $150^{\circ} \mathrm{C}$ for 30 minutes; c) after cooling at room temperature
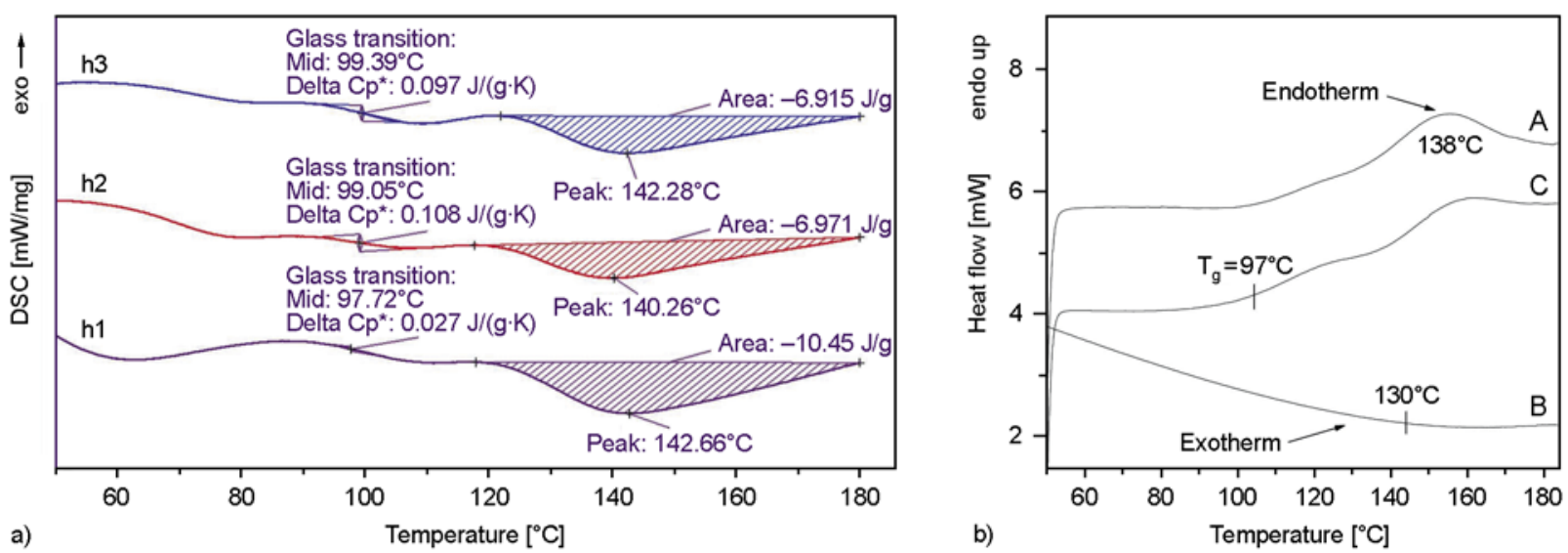

Figure 9. The DSC curves of model compound (a) (h1 - the first heating run; h2 - the second heating run and h3 -the third heating run) and PVFN-8 (b) (A - first heating; B - cooling; C - second heating) 
Figure $9 \mathrm{~b}$ shows the heating and cooling curves of DSC analysis of the PVFN-8 polymer. The curve ' $A$ ' shows the first heating cycle of the cross-linked polymer heated at 50 to $165^{\circ} \mathrm{C}$. It has an endothermic peak at $138^{\circ} \mathrm{C}$, which indicated the cleavage of the DA cross-links. The curve 'B' shows the cooling curve of the polymer. It shows a broad exothermic peak at $103-161^{\circ} \mathrm{C}$ (centering at about $130^{\circ} \mathrm{C}$ ) due to the covalent bond formation between furan and maleimide moieties, as the samples come closer on cooling and then finally reconnect very efficiently. The curve ' $\mathrm{C}$ ' shows the second heating cycle of the DA cross-linked polymer. It also shows the same observation in the first heating cycle. It clearly indicates that the Diels-Alder crosslinked polymer (PVFN-8) is thermoreversible. The $T_{\mathrm{g}}$ of the PVFN-8 polymer at $97^{\circ} \mathrm{C}$ was determined from the second heating cycle of the polymers and are shown in Figure 9. The shifting of $T_{\mathrm{g}}$ from $87^{\circ} \mathrm{C}$ (PVF-2) to $97^{\circ} \mathrm{C}$ is due to the DA cross-linked between PVF-2 and BMI-4.

The occurrence of the retro-DA reaction was also observed with ATR-FTIR. Figure 10a-c shows the ATR-FTIR spectra of PVFN-8 network film before heating at $150^{\circ} \mathrm{C}$ (Figure 10a), after heating at $150^{\circ} \mathrm{C}$ (Figure 10b) and after maintaining at $80^{\circ} \mathrm{C}$ for $3 \mathrm{~h}$ (Figure 10c). The PVFN-8 film spectrum (Figure 10a) evidences the intense absorption bands at 1709 and $1730 \mathrm{~cm}^{-1}$ attributed to $\mathrm{C}=\mathrm{O}$ stretching from urethane, ester or imide groups, $1536 \mathrm{~cm}^{-1}$ (amide II), $1395 \mathrm{~cm}^{-1}\left(\mathrm{C}-\mathrm{N}-\mathrm{C}\right.$ ), $1220 \mathrm{~cm}^{-1}$ (amide III) and $1159 \mathrm{~cm}^{-1}(\mathrm{C}-\mathrm{O}-\mathrm{C})$. The peak at $1776 \mathrm{~cm}^{-1}$ is attributed to the maleimide-furan cycloadduct

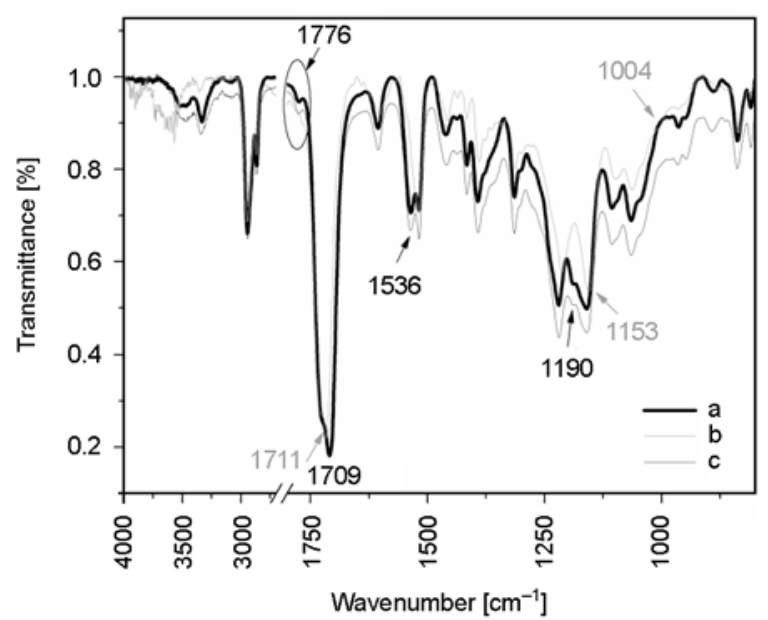

Figure 10. The ATR-FTIR spectra of PVFN-8: a) initial; b) heated at $150^{\circ} \mathrm{C}$; c) and after maintaining at $80^{\circ} \mathrm{C}$ for $3 \mathrm{~h}$
[38]. The spectrum ATR-FTIR of PVFN-8 after heating at $150^{\circ} \mathrm{C}$ (Figure $10 \mathrm{~b}$ ) presents a shift of absorption band characteristic to $\mathrm{C}=\mathrm{O}$ stretching from 1709 to $1711 \mathrm{~cm}^{-1}$ and the disappearance of the absorption bands at $1776 \mathrm{~cm}^{-1}$ attributed to the cycloadduct and at $1190 \mathrm{~cm}^{-1}$ corresponding to $\mathrm{C}-\mathrm{N}-\mathrm{C}$ (succinimide structure). The absorption band of amide II shifted to $1520 \mathrm{~cm}^{-1}$. The ATR-FTIR spectrum of network film after cooling at room temperature (Figure 10c) is identical to the initial spectrum.

In addition to the ATR-FTIR and DSC study, DMA was also employed to examine thermal behavior of the network materials. In Figures 11 and 12, the storage modulus $\left(E^{\prime}\right)$ and dissipation factor $(\tan \delta)$ curves of networks based on PVF and BMI, are plotted against temperature, and their data are presented in Table 1. As in DSC, DMA curves of the networks based on BMI-(1,2) show a single drop

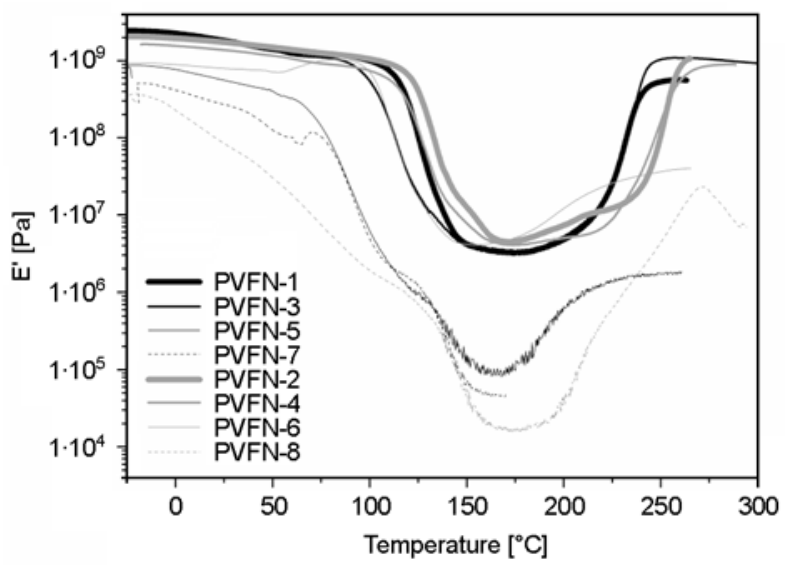

Figure 11. Storage modulus curves of PVFN networks based on PVF-1 (black line) and PVF-2 (grey line) with frequency of $1 \mathrm{~Hz}$ (with a heating rate of $2^{\circ} \mathrm{C} / \mathrm{min}$ )

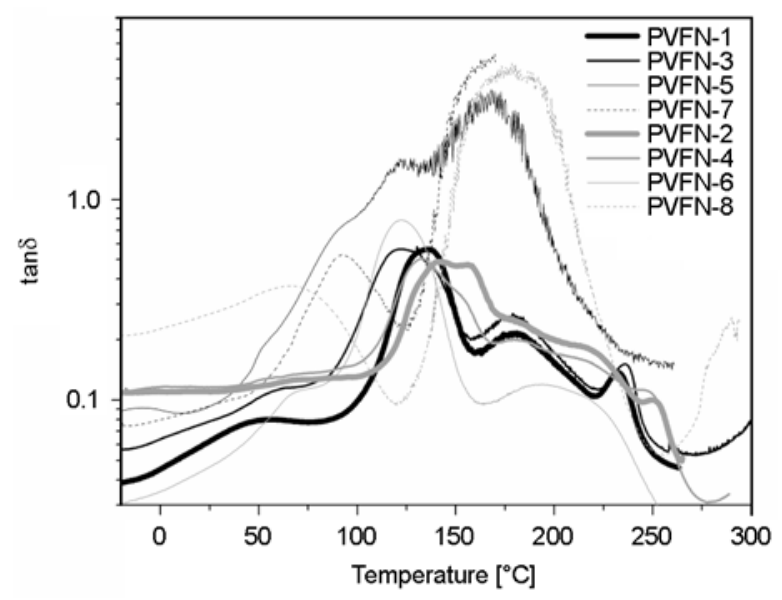

Figure 12. Dissipation factor $\tan \delta$ curves of PVFN networks with frequency of $1 \mathrm{~Hz}$ 
Table 3. The thermogravimetric data of PVA, PVF and PVFN

\begin{tabular}{|l|c|c|c|c|}
\hline \multirow{2}{*}{ Sample } & \multicolumn{3}{|c|}{ Decomposition temperature range (weight loss) [ $\left.^{\circ} \mathbf{C}\right]([\%])$} \\
\cline { 2 - 5 } PVA & Stage I & Stage II & Stage III & Stage IV \\
\hline PVF-1 & $20-232(3)$ & $260-385(42)$ & $385-470(26.8)$ & $470-630(16.8)$ \\
\hline PVFN-1 & $20-240(3)$ & $240-300(28.5)$ & $300-370(22)$ & $370-500(20) ; 510-670(20)$ \\
\hline PVFN-3 & $20-235(3)$ & $235-380(25)$ & $389-500(28)$ & $500-680(42)$ \\
\hline PVFN-5 & $20-235(2)$ & $245-405(32)$ & $405-520(22)$ & $520-720(36)$ \\
\hline PVFN-7 & $20-240(2)$ & $245-395(33)$ & $410-505(29)$ & $510-700(36)$ \\
\hline PVF-2 & $20-200(2)$ & $210-406(37)$ & $400-530(23)$ & $530-700(30)$ \\
\hline PVFN-2 & $20-235(2)$ & $240-370(43)$ & $370-500(21)$ & $500-630(29)$ \\
\hline PVFN-4 & $20-265(5)$ & $270-400(20)$ & $400-515(26)$ & $515-700(40)$ \\
\hline PVFN-6 & $20-270(1.5)$ & $270-403(20)$ & $405-510(25)$ & $515-720(38)$ \\
\hline PVFN-8 & $20-245(1.5)$ & $250-400(30)$ & $405-510(27)$ & $515-710(40)$ \\
\hline
\end{tabular}

attributed to the glass transition which overlaps with the retro-DA reaction and varied between 97.4 and $118.5^{\circ} \mathrm{C}$ (Table 1 ). The DMA curves of networks based on BMI-(3,4) show a decrease in two stages, first step is due to the glass transition and the second stage is assigned to the retro-DA reaction. This behaviour is concordance with the DSC diagrams (Figure 2) where the networks based on BMI-(1-2) presented a single inflexion while the networks based on BMI-(3,4) showed two inflexion points. The storage modulus of networks recovers above $200^{\circ} \mathrm{C}$ due to the thermal crosslinking reactions of the resulted bismaleimide from retroDA reactions and partial dehydration of PVA accompanied by polyene formation [43]. Figure 12 illustrated the temperature dependence of $\tan \delta$ for PVFN-(1-8) networks. Indeed, the relaxation process of networks appears structured into two components that can be tentatively attributed to the glass transition temperature of networks and retro-DA reactions. The second transition become prevailing for networks based on BMI- $(3,4)$ due to length of aliphatic chains of bismaleimide groups.

By processing TGA curves, thermal data presented in Table 3 resulted. The synthesized networks exhibited a four-step thermo-degradation curve. The weight loss at $20-265^{\circ} \mathrm{C}$ (in the first stage of decomposition) could be due to the residual solvents in the polymers (DMF and water). The second stage of decomposition ranged between $210-406^{\circ} \mathrm{C}$ with a weight loss of $20-36 \%$ corresponding to the elimination of water molecules from PVF chains [44] and acetic acid from acetate groups. In the third stages of decomposition, the breakdown of the polymer backbone takes place in the range of 389$530^{\circ} \mathrm{C}$ with a weight loss of $21-29 \%$. Specifically, it can be assigned to the degradation of nonconjugated polyene. The main decomposition of this process takes place in the range of $500-720^{\circ} \mathrm{C}$ corresponding to the weight loss of $31-42 \%$.

\subsubsection{Water absorption of networks}

The water absorption property of the samples was tested by their immersion in distilled water for 100 hours. Specimens were drawn, and the surface water was removed using a tissue paper and weighted to an accuracy of $0.001 \mathrm{~g}$. The water absorption versus time is plotted in Figure 13. As can be seen from figure, the moisture absorption of PVF-2based networks (having acetalization degree of $25 \%$ ) is considerably smaller than that of the series based on PVF-1.

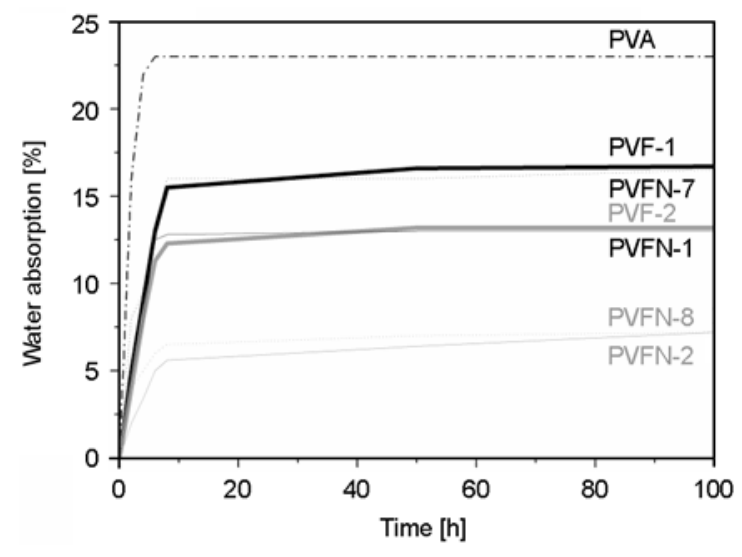

Figure 13. The water absorption versus time of the PVA, PVF and PVFN

\section{Conclusions}

Two series of polymers based on PVA modified with 2-furaldehyde have been synthetized and characterized using ATR-FTIR, ${ }^{1} \mathrm{H}-\mathrm{NMR}$, DSC, DMA, TGA analysis. The acetalization of PVA increases 
$T_{\mathrm{g}}$, value that increases more by cross-linking with BMI. The reversible nature of the cross-linked polymer was confirmed by ATR-FTIR spectroscopy and DSC analysis. In the DSC experiments the PVFBMI system shows a clear endotherm during heating, indicating the cleavage of the inter-monomer linkages; they also show an exotherm during cooling, indicating reconnection of the dienes and dienophiles. This hypothesis was corroborated by ATR-FTIR analysis during the heating/cooling cycle and DMA measurements. The $E^{\prime}$ curves for networks based on BMI-(1,2) show a single drop attributed to the glass transition which overlaps with the retro-DA reaction, while DMA curves of networks based on BMI- $(3,4)$ exhibit a two-stage decrease, first stage is attributed to the glass transition of polymers and the second stage is attributed to the retro Diels-Alder reaction.

High acetalization degree of PVF played an important role in reducing moisture absorption of the networks.

\section{References}

[1] Bergman S. D., Wudl F.: Re-mendable polymers. in 'Self healing materials: An alternative approach to 20 centuries of materials science' (ed.: van der Zwaag S.) Springer, Dordrecht, 45-68 (2007).

[2] Bergman, S. D., Wudl F.: Mendable polymers. Journal of Materials Chemistry, 18, 41-62 (2008).

DOI: $10.1039 / \mathrm{B} 713953 \mathrm{P}$

[3] Goiti E., Huglin M. B., Rego J. M.: Some properties of networks produced by the Diels-Alder reaction between poly(styrene-co-furfuryl methacrylate) and bismaleimide. European Polymer Journal, 40, 219226 (2004).

DOI: $10.1016 /$ j.eurpolymj.2003.09.017

[4] Wu D. Y., Meure S., Solomon D.: Self-healing polymeric materials: A review of recent developments. Progress in Polymer Science, 33, 479-522 (2008).

DOI: $10.1016 /$ j.progpolymsci.2008.02.001

[5] Chen X., Dam M. A., Ono K., Mal A., Shen H., Nutt S. R., Sheran K., Wudl F.: A thermally re-mendable crosslinked polymeric material. Science, 295, 1698-1702 (2002).

DOI: $10.1126 /$ science. 1065879

[6] Boul P. J., Reutenauer P., Lehn J-M.: Reversible DielsAlder reactions for the generation of dynamic combinatorial libraries. Organic Letters, 7, 15-18 (2005). DOI: $10.1021 / 01048065 \mathrm{k}$
[7] Mcelhanon J. R., Russick E. M., Wheeler D. R., Loy D. A., Aubert J. H.: Removable foams based on an epoxy resin incorporating reversible Diels-Alder adducts. Journal of Applied Polymer Science, 85, 1496-1502 (2002).

DOI: $10.1002 / a p p .10753$

[8] Chen X., Wudl F., Mal A. K., Shen H., Nutt S. R.: New thermally remendable highly cross-linked polymeric materials. Macromolecules, 36, 1802-1807 (2003). DOI: $10.1021 / \mathrm{ma} 0210675$

[9] Goiti E., Heatley F., Huglin M. B., Rego J. M.: Kinetic aspects of the Diels-Alder reaction between poly (styrene-co-furfuryl methacrylate) and bismaleimide. European Polymer Journal, 40, 1451-1460 (2004). DOI: $10.1016 / j$.eurpolymj.2004.01.036

[10] Watanabe M., Yoshie N.: Synthesis and properties of readily recyclable polymers from bisfuranic terminated poly(ethylene adipate) and multi-maleimide linkers. Polymer, 47, 4946-4952 (2006).

DOI: 10.1016/j.polymer.2006.05.036

[11] Liu Y-L., Hsieh C-Y.: Crosslinked epoxy materials exhibiting thermal remendablility and removability from multifunctional maleimide and furan compounds. Journal of Polymer Science Part A: Polymer Chemistry, 44, 905-913 (2006).

DOI: $10.1002 /$ pola. 21184

[12] Tian Q., Rong M. Z., Zhang M. Q., Yuan Y. C.: Synthesis and characterization of epoxy with improved thermal remendability based on Diels-Alder reaction. Polymer International, 59, 1339-1345 (2010). DOI: $10.1002 /$ pi.2872

[13] Tian Q., Yuan Y. C., Rong M. Z., Zhang M. Q.: A thermally remendable epoxy resin. Journal of Materials Chemistry, 19, 1289-1296 (2009) DOI: $10.1039 / \mathrm{B} 811938 \mathrm{D}$

[14] Ishida K., Yoshie N.: Two-way conversion between hard and soft properties of semicrystalline cross-linked polymer. Macromolecules, 41, 4753-4757 (2008). DOI: $10.1021 / \mathrm{ma} 8008383$

[15] Aumsuwan N., Urban M. W.: Reversible releasing of arms from star morphology polymers. Polymer, 50, 3336 (2009).

DOI: $10.1016 /$ j.polymer.2008.10.048

[16] Gousé C., Gandini A., Hodge P.: Application of the Diels-Alder reaction to polymers bearing furan moieties. 2. Diels-Alder and retro-Diels-Alder reactions involving furan rings in some styrene copolymers. Macromolecules, 31, 314-321 (1998).

DOI: $10.1021 / \mathrm{ma9710141}$

[17] Goiti E., Huglin M. B., Rego J. M.: Some observations on the copolymerization of styrene with furfuryl methacrylate. Polymer, 42, 10187-10193 (2001). DOI: 10.1016/S0032-3861(01)00577-8 
[18] Goiti E., Huglin M. B., Rego J. M.: Thermal breakdown by the retro Diels-Alder reaction of crosslinking in poly[styrene-co-(furfuryl methacrylate)]. Macromolecular Rapid Communications, 24, 692-696 (2003). DOI: 10.1002/marc.200350013

[19] Gheneim R., Perez-Berumen C., Gandini A.: DielsAlder reactions with novel polymeric dienes and dienophiles: Synthesis of reversibly cross-linked elastomers. Macromolecules, 35, 7246-7253 (2002). DOI: $10.1021 / \mathrm{ma} 020343 \mathrm{c}$

[20] Kavitha A. A., Singha N. K.: A tailor-made polymethacrylate bearing a reactive diene in reversible Diels-Alder reaction. Journal of Polymer Science Part A: Polymer Chemistry, 45, 4441-4449 (2007). DOI: $10.1002 /$ pola.22195

[21] Liu Y-L., Chen Y-W.: Thermally reversible crosslinked polyamides with high toughness and self-repairing ability from maleimide- and furan-functionalized aromatic polyamides). Macromolecular Chemistry and Physics, 208, 224-232 (2007).

DOI: $10.1002 /$ macp. 200600445

[22] Kavitha A. A., Singha N. K.: Atom-transfer radical copolymerization of furfuryl methacrylate (FMA) and methyl methacrylate (MMA): A thermally-amendable copolymer. Macromolecular Chemistry and Physics, 208, 2569-2577 (2007).

DOI: $10.1002 / \mathrm{macp} .200700239$

[23] Zhu J., Kell A. J., Workentin M. S.: A retro-DielsAlder reaction to uncover maleimide-modified surfaces on monolayer-protected nanoparticles for reversible covalent assembly. Organic Letters, 8, 49934996 (2006).

DOI: $10.1021 / 010615937$

[24] Imai Y., Itoh H., Naka K., Chujo Y.: Thermally reversible IPN organic-inorganic polymer hybrids utilizing the Diels-Alder reaction. Macromolecules, 33, 4343-4346 (2000). DOI: $10.1021 / \mathrm{ma991899b}$

[25] Adachi K., Achimuthu A. K., Chujo Y.: Synthesis of organic-inorganic polymer hybrids controlled by Diels-Alder reaction. Macromolecules, 37, 97939797 (2004).

DOI: $10.1021 / \mathrm{ma} 0400618$

[26] Liu Y-L., Hsieh C-Y., Chen Y-W.: Thermally reversible cross-linked polyamides and thermo-responsive gels by means of Diels-Alder reaction. Polymer, 47, 25812586 (2006).

DOI: $10.1016 /$ j.polymer.2006.02.057

[27] Zhang Y., Broekhuis A. A., Picchioni F.: Thermally self-healing polymeric materials: The next step to recycling thermoset polymers? Macromolecules, 42, 1906-1912 (2009).

DOI: $10.1021 / \mathrm{ma} 8027672$

[28] Teramoto N., Arai Y., Shibata M.: Thermo-reversible Diels-Alder polymerization of difurfurylidene trehalose and bismaleimides. Carbohydrate Polymers, 64, 78-84 (2006). DOI: $10.1016 /$ j.carbpol.2005.10.029
[29] Gandini A., Coelho D., Silvestre A. J. D.: Reversible click chemistry at the service of macromolecular materials. Part 1: Kinetics of the Diels-Alder reaction applied to furan-maleimide model compounds and linear polymerizations. European Polymer Journal, 44, 4029-4036 (2008).

DOI: $10.1016 /$ j.eurpolymj.2008.09.026

[30] Jegat C., Mignard N.: Effect of the polymer matrix on the thermal behaviour of a furan-maleimide type adduct in the molten state. Polymer Bulletin, 60, 799-808 (2008). DOI: $10.1007 / \mathrm{s} 00289-008-0913-\mathrm{y}$

[31] Canadell J., Fischer H., De With G., Van Benthem R. A. T. M.: Stereoisomeric effects in thermo-remendable polymer networks based on Diels-Alder crosslink reactions. Journal of Polymer Science Part A: Polymer Chemistry, 48, 3456-3467 (2010).

DOI: $10.1002 /$ pola.24134

[32] Mikroyannidis J. A.: Thermostable laminating resins based on aromatic diketone bis- and tetramaleimides. Journal of Polymer Science Part A: Polymer Chemistry, 28, 679-691 (1990).

DOI: $10.1002 /$ pola.1990.080280317

[33] Cristea M., Gaina C., Gheorghiu Ionita D., Gaina V.: Dynamic mechanical analysis on modified bismaleimide resins. Journal of Thermal Analysis and Calorimetry, 93, 69-76 (2008).

DOI: $10.1007 /$ s10973-007-8802-4

[34] Gaina V., Gaina C., Sava M., Stoleriu A., Rusu M.: Bismaleimide resins containing urethanic moieties. Journal of Macromolecular Science Part A: Pure and Applied Chemistry, 34, 2435-2449 (1997).

DOI: $10.1080 / 10601329708010058$

[35] Gousse C., Gandini A.: Acetalization of polyvinyl alcohol with furfural. European Polymer Journal, 33, 667-671 (1997).

DOI: 10.1016/S0014-3057(96)00234-0

[36] Chetri P., Dass N. N.: Synthesis of poly(vinyl benzal) from poly(vinyl alcohol) in nonaqueous medium. Journal of Applied Polymer Science, 62, 2139-2145 (1996).

DOI: $10.1002 /(\mathrm{SICI}) 1097-4628(19961219) 62: 12<2139$ $\because$ AID-APP16>3.0.CO;2-0

[37] Fernández M. D., Fernández M. J., Hoces P.: Poly (vinyl acetal)s containing electron-donor groups: Synthesis in homogeneous phase and their thermal properties. Reactive and Functional Polymers, 68, 39-56 (2008).

DOI: 10.1016/j.reactfunctpolym.2007.10.012

[38] Adriaensens P., Pollers I., Carleer R., Vanderzande D., Gelan J.: Solid-state NMR study of different types of poly(vinyl formal). Macromolecules, 32, 440-447 (1999).

DOI: $10.1021 / \mathrm{ma981216c}$ 
[39] Cerrada M. L., Benavente R., Pérez E., Pereña J. M.: The effect of orientation on the morphology and viscoelastic response of vinyl alcohol-ethylene copolymers. Macromolecular Chemistry and Physics, 201, 1858-1868 (2000).

DOI: $10.1002 / 1521-3935(20000901) 201: 14<1858:$ : AID-MACP1858>3.0.CO;2-A

[40] Park J-S., Park J-W., Ruckenstein E.: On the viscoelastic properties of poly(vinyl alcohol) and chemically crosslinked poly(vinyl alcohol). Journal of Applied Polymer Science, 82, 1816-1823 (2001).

DOI: 10.1002/app.2023

[41] Park J-S., Park J-W., Ruckenstein E.: A dynamic mechanical and thermal analysis of unplasticized and plasticized poly(vinyl alcohol)/methylcellulose blends. Journal of Applied Polymer Science, 80, 1825-1834 (2001).

DOI: $10.1002 / a p p .1278$
[42] Tian Q., Rong M. Z., Zhang M. Q., Yuan Y. C.: Optimization of thermal remendability of epoxy via blending. Polymer, 51, 1779-1785 (2010).

DOI: $10.1016 /$ j.polymer.2010.02.004

[43] Shaulov A. Yu., Lomakin S. M., Zarkhina T. S., Rakhimkulov A. D., Shilkina N. G., Muravlev Yu. B., Berlin Al. Al.: Carbonization of poly(vinyl alcohol) in blends with boron polyoxide. Doklady Physical Chemistry, 403, 154-158 (2005).

DOI: $10.1007 / \mathrm{s} 10634-005-0048-\mathrm{x}$

[44] Alexy P., Káchová D., Kršiak M., Bakoš D., Šimková B.: Poly(vinyl alcohol) stabilisation in thermoplastic processing. Polymer Degradation and Stability, 78, 413-421 (2002).

DOI: $10.1016 / \mathrm{S} 0141-3910(02) 00177-5$ 